NASA/TM-2008-215452

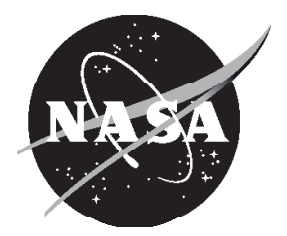

\title{
Assuring Life in Composite Systems
}

\author{
Christos C. Chamis \\ Glenn Research Center, Cleveland, Ohio
}




\section{NASA STI Program . . . in Profile}

Since its founding, NASA has been dedicated to the advancement of aeronautics and space science. The NASA Scientific and Technical Information (STI) program plays a key part in helping NASA maintain this important role.

The NASA STI Program operates under the auspices of the Agency Chief Information Officer. It collects, organizes, provides for archiving, and disseminates NASA's STI. The NASA STI program provides access to the NASA Aeronautics and Space Database and its public interface, the NASA Technical Reports Server, thus providing one of the largest collections of aeronautical and space science STI in the world. Results are published in both non-NASA channels and by NASA in the NASA STI Report Series, which includes the following report types:

- TECHNICAL PUBLICATION. Reports of completed research or a major significant phase of research that present the results of NASA programs and include extensive data or theoretical analysis. Includes compilations of significant scientific and technical data and information deemed to be of continuing reference value. NASA counterpart of peer-reviewed formal professional papers but has less stringent limitations on manuscript length and extent of graphic presentations.

- TECHNICAL MEMORANDUM. Scientific and technical findings that are preliminary or of specialized interest, e.g., quick release reports, working papers, and bibliographies that contain minimal annotation. Does not contain extensive analysis.

- CONTRACTOR REPORT. Scientific and technical findings by NASA-sponsored contractors and grantees.

- CONFERENCE PUBLICATION. Collected papers from scientific and technical conferences, symposia, seminars, or other meetings sponsored or cosponsored by NASA.

- SPECIAL PUBLICATION. Scientific, technical, or historical information from NASA programs, projects, and missions, often concerned with subjects having substantial public interest.

- TECHNICAL TRANSLATION. Englishlanguage translations of foreign scientific and technical material pertinent to NASA's mission.

Specialized services also include creating custom thesauri, building customized databases, organizing and publishing research results.

For more information about the NASA STI program, see the following:

- Access the NASA STI program home page at http://www.sti.nasa.gov

- E-mail your question via the Internet to help@ sti.nasa.gov

- Fax your question to the NASA STI Help Desk at 301-621-0134

- Telephone the NASA STI Help Desk at 301-621-0390

- Write to: NASA Center for AeroSpace Information (CASI) 7115 Standard Drive Hanover, MD 21076-1320 
NASA/TM—2008-215452

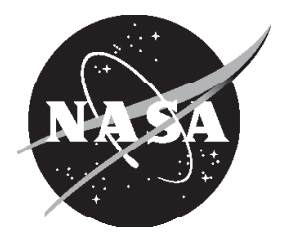

\title{
Assuring Life in Composite Systems
}

\author{
Christos C. Chamis
}

Glenn Research Center, Cleveland, Ohio

National Aeronautics and

Space Administration

Glenn Research Center

Cleveland, Ohio 44135 


\section{Acknowledgments}

The author expresses his sincere appreciation to Galib H. Abumeri who developed the computer simulations required for this paper.

This report is a formal draft or working paper, intended to solicit comments and ideas from a technical peer group.

Level of Review: This material has been technically reviewed by technical management.

Available from

NASA Center for Aerospace Information 7115 Standard Drive

Hanover, MD 21076-1320
National Technical Information Service 5285 Port Royal Road Springfield, VA 22161

Available electronically at http://gltrs.grc.nasa.gov 


\title{
Assuring Life in Composite Systems
}

\author{
Christos C. Chamis \\ National Aeronautics and Space Administration \\ Glenn Research Center \\ Cleveland, Ohio 44135
}

\begin{abstract}
A computational simulation method is presented to assure life in composite systems by using dynamic buckling of smart composite shells as an example. The combined use of composite mechanics, finite element computer codes, and probabilistic analysis enable the effective assessment of the dynamic buckling load of smart composite shells. A universal plot is generated to estimate the dynamic buckling load of composite shells at various load rates and probabilities. The shell structure is also evaluated with smart fibers embedded in the plies right below the outer plies. The results show that, on the average, the use of smart fibers improved the shell buckling resistance by about $9 \%$ at different probabilities and delayed the buckling occurrence time. The probabilistic sensitivities results indicate that uncertainties in the fiber volume ratio and ply thickness have major effects on the buckling load. The uncertainties in the electric field strength and smart material volume fraction have moderate effects and thereby in the assured life of the shell.
\end{abstract}

\section{Introduction}

Shell structures are in general capable of resisting combined loading conditions. They are widely used in aircrafts, in submarines, in transportation and in storage industries. Thin composite shells are susceptible to instabilities (buckling) when subjected to compressive static loads. In more aggressive loading environments, they may also be subjected to dynamic or time dependent loads. Assuring the resistance of thin shells due to buckling is a rather difficult task because of the assumptions that need to be made in order to obtain results that are representative of the physical situation. Advances in the area of structural finite element analysis enabled the evaluation of the buckling load of thin composite shells under dynamic loading. Evaluation of the dynamic buckling of composite shells has been recently performed as described in reference 1. However, evaluation of the dynamic buckling of adaptive composite shells and their assured life have not been performed as of this writing. Therefore, the work presented here describes a formal approach for the evaluation of the deterministic and nondeterministic buckling of adaptive composite shells. The adaptive structure considered here integrates smart fibers in the composite shell to enhance its structural performance and thereby its life.

Recent developments in the application of smart structures concepts, using sensor/control materials, show the potential to enhance structural performance as well as durability and reliability (ref. 2). Briefly, sensor/control devices consist of the following: (1) an electronically polarized material, (2) an electric field parallel to the direction of polarization, and (3) expansion and contraction effects of the polarized material. When control voltages are applied in the direction of polarization during normal operation, the sensor/control material expands in the same direction so that the structural behavior is altered by a desired amount; thus, its reliability is enhanced. These control voltages can be readily integrated into a smart composite structure by using combinations of intraply and interply hybrid composites. It is then possible to ensure that smart structures will operate in the design-specified range. The fundamentals associated with the prediction of the dynamic buckling load of composite shells are discussed in the next section. 


\section{Fundamentals}

The dynamic buckling load obtained from the use of smart fibers is assessed using a computational simulation system that combines composite mechanics (ICAN) (ref. 3) and finite element analysis (MHOST) (ref. 4) computer codes. The integrated composite analyzer computer code ICAN performs all the essential aspects of mechanics/analysis/design of multilayered fiber composites. Modular, open-ended and user friendly, the program can handle a variety of composite systems having one type of fiber and one matrix as constituents as well as intraply and interply hybrid (ref. 5) composite systems. It can also simulate isotropic layers by considering a primary composite system with negligible fiber volume content. This feature is specifically useful in modeling thin interply matrix layers. Hygrothermal conditions and various combinations of in-plane and bending loads can also be considered. Some key features of output are stress concentration factors around a circular hole, locations of probable delamination, a summary of the laminate failure stress analysis, free edge stresses, microstresses and ply stress/strain influence coefficients. These features make ICAN a powerful, cost-effective tool to analyze/design fiber composite structures and components. MHOST is a solid and structural analysis program based on mixed finite element technology, and is specifically designed for three-dimensional inelastic analysis. A family of two- and three-dimensional continuum elements along with beam and shell structural elements can be utilized.

The effects of uncertainties in the material properties, fabrication, and smart composite primitive variables on the dynamic buckling load of the composite shell are assessed through the IPACS (ref. 6) computer code. IPACS combines composite mechanics with finite element analysis and probabilistic methods. Given the probability distributions for the primitive variables, and an estimated relationship between the structural response and the primitive variables, a computationally efficient method is used to obtain accurate probability and response predictions by using approximate methods for evaluating structural reliability.

The technical approach used in the dynamic buckling evaluation of conventional composite shells is described subsequently. It includes an explanation of a universal plot constructed for a graphite epoxy shell subjected to dynamic axial compressive loading. This is followed by an explanation of the concept that adapts intraply hybrid composite to smart shell structures. Then a discussion of the deterministic results obtained with the use of smart fibers in the outer $-45^{\circ}$ plies is presented. After that, probabilistic evaluation of the dynamic buckling load for the graphite epoxy smart composite shell is discussed. The probabilistic analysis includes an evaluation of the sensitivities where the effect of the primitive variables on the dynamic buckling load is assessed with respect to the shells life assurance. Dynamic buckling analysis of the composite shell performed after re-arranging the orientation of plies 1 and 30 shows that improvement in buckling resistance can be attained without resorting to complicated material systems (such as those of piezoelectric fibers).

\section{Dynamic Buckling of a Conventional Composite Shell}

The estimation of the dynamic buckling load of a conventional graphite epoxy composite shell is based on the governing equation for dynamic structural response in matrix form:

$$
\lfloor M]\{\ddot{\mathrm{u}}\}+\lfloor C \mid\{\dot{u}\}+\lfloor K\rfloor\{u\}=\{F(t)\}
$$

where $M$ is the mass; $C$ is the damping; $K$ is the stiffness and $F$ is the forcing function; $\ddot{\mathrm{u}}$ is the acceleration, $\dot{u}$ is the velocity and $u$ is the displacement. Equation (1) is of generic form and represents the single or multidegrees of freedom structures. Dynamic buckling is obtained by solving equation (1) as a linear eigen value problem or as a large displacement amplitude problem by using the updated Lagrangian method. Available structural analysis finite element computer codes/programs have both options (ref. 7). In this approach, updates for material properties, temperature changes, geometric deformations, adaptive structure corrective actions, and structural damage are readily incorporated as they 
occur in time. The dynamic buckling load is obtained at each time step by first satisfying equation (1), including iteration when necessary, and then solve for the buckling load from the equation:

$$
([K]-[F(t)]\{u\})=\lambda^{2}\{u\}
$$

The specific shell evaluated is depicted schematically in figure 1 where the material and loading conditions are also shown. The shell is assumed to be made from AS graphite-fiber/epoxy-matrix composite with the laminate configuration: $\left[(45,-45,0,90)_{7},-45,45\right]$. The buckling load predicted by using Equation (2) versus incremented dynamic load is shown in figure 2 . As can be seen, the dynamic buckling load decreases monotonically approaching asymptotically a value that is about $50 \%$ of the initial value (at $t=0$ ). As illustrated in figure 2, superimposing the increasing dynamic force in the same graph with the dynamic buckling load, the dynamic buckling load can be determined from the intersection of the two curves. The author consider the results in figure 2 as demonstration of a straightforward procedure to evaluate dynamic buckling loads of composite shell structures by using available general purpose structural analysis, finite element and composite mechanics computer codes. The approach is not limited to linearly incremented dynamic loads, although the author has not checked it for nonlinearly incremented loads or for "suddenly" $(t \approx 0)$ applied loads. The method presented here is generic and not restricted to any special class of shells and/or loading conditions. A description of the approach used in the intraply hybrid composite adaptation to the smart composite shell is presented in the next section.

\section{Adaptation of Hybrid Composites to Smart Shells}

The adaptation of the intraply hybrid composite concept to the smart shell composite structure is depicted schematically in figure 3 . The configuration of the intraply hybrid composite is shown in figure 3(a). Its adaptation to smart composite system is shown in figure 3(b). Note that the intraply hybrid composite consists of plies that have strips of a regular (host) composite material and interspersed strips of material for sensor/control devices. Actuators, made of control materials such as piezoelectric ceramic fiber, are used to control the behavior of the composite structure by expanding (positive-induced strain) or contracting (negative-induced strain) the sensor/control strips to achieve the requisite design and operational goals. The strains induced by the actuator are affected by uncertainties in several factors that can only be quantified probabilistically. These include the following: (1) inaccurate measurements made by the sensors, (2) uncertainties in the electric field, (3) uncertain induced strain-electric field strength relationship, (4) uncertain material properties for the sensor/control materials, (5) uncertain electric filed strength, and (6) improper location of the sensor/control materials. Because of these factors, the use of sensor/control devices increases the uncertainty in the already uncertain composite structural behavior.

The mean properties for the smart (piezoelectric) fiber are tabulated in figure 4 . The properties include the moduli, strain coefficient, field strength, and material volume fraction. The smart fiber is embedded in the outer $-45^{\circ}$ ply (right below the outer $45^{\circ}$ ply). The smart composite shell is assumed to be made from graphite epoxy with piezoelectric fibers embedded in plies 2 and 29 as shown in figure 4. To properly quantify the benefits of introduced strain, a comprehensive probabilistic assessment is needed. Table I summarizes the mean constituent material properties and fabrication variables, their assumed probabilistic distribution, and the range of the scatter. Table I also lists the corresponding smart (sensor/control) composite variables. Those variables include the field strength, field strain coefficient, smart material volume fraction, and thickness of smart ply. The computational procedure used in assessing the smart composite shell consists of the following: (1) the control strains are simulated using equivalent variables principles. The thermal strain is computed from uncertain temperature (representing the electric field strength) and uncertain thermal expansion coefficients (representing the sensor/control strain coefficients); these thermal strains are in addition to those from thermal loads; and (2) the scatter in the primitive variables, which describes the composite, can be presented by known probabilistic 
distributions. The results obtained from the deterministic evaluation of the dynamic buckling load of the smart composite shell are presented next.

\section{Deterministic Dynamic Buckling of Smart Composite Shells}

The dynamic buckling load of the smart composite shell is assessed using the configuration shown in figure 4. As mentioned previously, induced control strains are simulated using equivalent variables principles. Temperature loads representing the electric field strength are applied to the plies that include smart fibers. The thermal expansion coefficients are used to represent the strain coefficients. At the end of each time step, buckling analysis is performed by satisfying equation (1). The smart shell geometry is updated at the end of each time step to including time dependent deformations. The results obtained from the dynamic buckling analysis are presented in figure 5. The dynamic buckling load of the smart composite shell is $7.43 \mathrm{GN}$ (1671 kips) compared to $6.85 \mathrm{GN}$ (1540 kips) for the conventional composite shell. The $8.5 \%$ improvement in the dynamic buckling load for the shell that comprises the smart material is resulting from field strength of $25,400 \mathrm{~V} / \mathrm{m}\left(625 \mathrm{~V} /\right.$ in .), a strain coefficient of $1.22 \times 10^{-10} \mathrm{~V} / \mathrm{m}$ $\left(4.8 \times 10^{-9}\right)$ in./ $\mathrm{V}$, smart fiber volume ratio of 0.65 , and a smart material volume fraction of $0.5 \%$. As depicted in figure 5, for any time $t$, the buckling load of the smart shell is consistently higher than the one of the conventional composite shell. Also, the dynamic buckling of the smart composite shell requires longer time before it occurs. Weight analysis of the smart and conventional composite shells indicates that the smart shell is about $9 \%$ heavier than the conventional one. The weight of the smart shell is estimated at $276.8 \mathrm{~N}(51 \mathrm{lb})$ compared to $209.1 \mathrm{~N}(47 \mathrm{lb})$ for the conventional graphite epoxy shell. The IPACS computer code used to perform the nondeterministic analysis of the dynamic buckling load of the smart composite shell is described next.

\section{Description of the IPACS Computer Code}

The probabilistic structural analysis is performed using the integrated probabilistic assessment of composite structures computer code IPACS. With the direct coupling of composite mechanics, including interply and intraply hybrids using ICAN, finite element structural analysis (MHOST), and probabilistic methods, IPACS is capable of simulating uncertainties in all inherent scales of the composite, from constituent materials to the composite structure and its loading conditions. The evaluation process starts with the identification of the primitive variables at the micro and macro composites scales including fabrication. These variables are selectively perturbed in order to generate a database for the determination of the relationships between the desired primitive variables behavior and/or structural response of the smart composite shell.

The composite micro-mechanics is used to carry over the scatter in the primitive variables to the ply and laminate scales (steps A and B in figure 6). Laminate theory is then used to determine the scatter in the material behavior at the laminate scale (step C). This step leads to the perturbed resultant force/moment-displacement/curvature relationships used in the structural analysis. Next, the finite element analysis is performed to determine the perturbed structural responses corresponding to the selectively perturbed primitive variables (step D). This completes the description of the hierarchical composite material/structure synthesis shown on the left side of figure 6 . The multi scale progressive decomposition of the structural response to the laminate, ply, and fiber-matrix constituent scales is shown on the right side of figure 6 (steps E to G). After the decomposition, the perturbed fiber, matrix, and ply stresses can be determined. An important feature of IPACS, depicted at the bottom of figure 6 , is the nonlinear multifactor interaction model for computing the fiber-matrix constituent material properties, including the effects of the prevailing service environments.

Next, the fast probability integrator (FPI) (ref. 8) code is used to determine the functional relationship between the response and the primitive variables. The cumulative distribution function of the response is then calculated with the numerically determined functional relationship and the known probability density 
functions of the primitive variables. The sensitivity factors of the primitive variables to each response's cumulative probability are also determined. This information is crucial for the reliability assessment.

\section{Nondeterministic Dynamic Buckling of Smart Composite Shells}

The nondeterministic evaluation of the dynamic buckling load for the smart composite shell is performed based on the scatter in the fiber and matrix material properties, fabrication variables, and smart composite field and material properties. The following scatter is assumed for the various primitive variables: $( \pm 5 \%)$ for the graphite fiber and smart fiber longitudinal moduli, and ply thickness; $( \pm 6.67 \%)$ for the ply angle; $( \pm 10 \%)$ for the graphite fiber and smart fiber shear moduli, fiber and matrix density, matrix modulus, fiber volume ratio, smart material volume fraction, electric field strength, and strain coefficient; and $( \pm 15 \%)$ for the void volume ratio. Table I lists the probabilistic distributions and standard deviations for all primitive variables. Note that the perturbations are performed in the probabilistic analysis module for the properties and fabrication variables of the graphite epoxy laminates, and for the laminates that contain the graphite epoxy (primary material system) and smart composite (secondary material system). The probabilistic dynamic buckling load for the all graphite epoxy composite and smart composite (graphite epoxy and smart material) is presented in figure 7. For a probability of occurrence of $1 / 1000$, the smart composite dynamic buckling load is $9.7 \%$ higher than that of the all graphite epoxy composite shell. The same trend is observed for the 0.5 and 0.999 probabilities where the smart composite buckling resistance is enhanced by about $8.7 \%$. Note the parallel shift in the cumulative distribution function curve to the right in the case of the smart composite shell, which indicates a uniform improvement in the probabilistic dynamic buckling load. Therefore, the life assurance of the smart dynamic buckling shell is about $9 \%$.

The probabilistic sensitivities of the dynamic buckling load for the smart composite shell are presented in figure 8 . The material properties primitive variables include: fiber modulus in longitudinal direction, fiber shear modulus, fiber density, matrix modulus, and matrix density. The fabrication primitive variables considered are: fiber volume ratio, void volume ratio, fiber orientation and ply thickness. Note that the material properties and fabrication primitive variables apply to the graphite epoxy and smart fiber and epoxy matrix of the smart composite shell structure. The primitive variables specific to the smart fiber are: electric field strength, strain coefficient, and volume fraction of the smart material. The sensitivity analysis shows that the dominant uncertainties are the ply thickness and fiber volume ratio for the whole composite system (primary and secondary). The smart material sensitivity analysis indicates that the electric field strength and volume fraction are the dominant uncertainties followed in that order by the strain coefficient. Information obtained from sensitivity analysis can be very useful in altering the design to meet specific service and life assurance requirements. That is done by controlling the scatter in critical primitive variables which have dominant effect on the structural response. In addition to sensitivity analysis, the 0.001 and 0.999 probabilities buckling loads are plotted as a function of time and the applied load in figures 9 and 10, respectively. The advantage of using smart material is assessed by noting the upward shift in the buckling load curve. The smart structure probabilistic buckling load is higher than that of the conventional shell probabilistic load by about $10 \%$. Also, the time at which the dynamic buckling occurs is delayed as a result of the use of smart material. The probabilistic dynamic buckling load evaluation is unique because it allows the construction of a universal plot for evaluating the dynamic buckling load at any probability taking into account the effect of time and load on the structural response. In the next section, results are presented and discussed for the dynamic buckling analysis that is performed after the simple re-arrangement of the orientation of the outer plies of the composite shell. The analysis is performed twice: without and with smart material. 


\section{Benefits of Rearranging the Plies on The Outer Surfaces}

The dynamic buckling load is assessed for the conventional graphite epoxy shell with re-arranged outer fiber orientation. The analysis is carried out based on orienting the fibers in plies 1 and 30 at $0^{\circ}$ and $90^{\circ}$, respectively. This simple re-arrangement leads to an improvement of $15 \%$ in the buckling load (fig. 11). The shell now buckles under a dynamic load of 7.9 GN (1770 kips), compared to 6.8 GN (1540 kips) with $+45^{\circ}$ outer plies. Figure 12 shows the dynamic buckling results for another fiber orientation arrangement: ply 1 and ply 30 are now oriented at $90^{\circ}$. With such an arrangement, the dynamic buckling load improved 16\%. In addition to improving the buckling resistance of the composite shell, the time at which dynamic buckling takes place is delayed. The results in figures 11 and 12 show that for the specific shell, fiber orientation rearrangement is more beneficial than using smart material. Dependent on the loading, one must ensure that proposed changes in the fiber orientation, especially on the inside and outside surfaces, do not pose other structural risks such as premature fracture. Proper engineering judgment is always needed to justify changes in the layout of a composite structure.

The composite shell structure, with ply 1 and ply 30 oriented at $0^{\circ}$ and $90^{\circ}$, is analyzed with smart fibers embedded in plies 2 and 29 (as depicted in figure 4). The dynamic buckling analysis results show that the use of smart materials lowered the buckling load of the composite shell about $6.7 \%$ (fig. 13). When the composite shell ply 1 and ply 30 are oriented at $90^{\circ}$ and smart fibers are embedded in plies 2 and 29, the dynamic buckling analysis shows that the shell's buckling resistance is weakened $2.5 \%$ (fig. 14). For the cases described in this section, the reduction in the dynamic buckling load in the presence of smart material is caused by a reversal in the effect of the control strain. As a result, the buckling resistance of the composite shell has decreased.

\section{Life Assessment}

The life assessment was mentioned in several places throughout the text. There is a more reasonable way to make that assessment based on the Cumulative Distribution Function. This function includes all the probabilities from " 0 " to " $\infty$ ". The life assessment is performed by the probability that an event will occur at a probability level. We want to evaluate the life assurance at a high probability level. Let us decide that it will be at a point of 0.999 probability. Then we calculate the probability of failure at 0.001 . Now the life assurance will be at ( 1 to 0.001 ) or 0.999 . Checking the table in figure 7 we get values for the all graphite composite shell of $14.3 \mathrm{GN}$ (3210 kips) and for the smart shell a value of $15.6 \mathrm{GN}$ (3514 kips). Comparing these values to those at the 0.5 probability, we obtain $108 \%$ for the all graphite composite shell and $120 \%$ for the smart shell. Therefore, the life assurance of the two shells is about two times their average values at 0.5 probability.

\section{Conclusions}

The generic combination of conventional finite element method, available composite mechanics, smart structure concepts and incrementally updated Lagrangian solution algorithm is computationally efficient and sufficient for evaluating the dynamic buckling load of thin shells and thereby their respective life assurance. The method is demonstrated for conventional and smart composite shells. In addition to deterministic results, uncertainties in property, fabrication, and smart material primitive variables and their effects on the dynamic buckling load are discussed. The following specific conclusions are also drawn:

(1) The universal plot developed for estimating the dynamic buckling load of conventional shells can be equally applied to determine the dynamic buckling load of smart composite shells.

(2) The use of smart fibers in a thin graphite epoxy shell improved the buckling resistance by $9 \%$ and thereby the life assurance of the all graphite composite shell by $9 \%$ as well. 
(3) Uncertainties in the smart material volume fraction and field strength have moderate effects on the buckling load while uncertainty in the fiber volume ratio, and ply thickness have major effects.

(4) For the shell considered in this evaluation, benefits obtained from the use of smart material can be surpassed by the simple re-arrangement of the fiber orientation of the outer plies.

(5) The life assessment of the two shells evaluated from the Cumulative Distribution Function is about twice their at 0.5 probability.

\section{References}

1. X. Huyan and G.J. Simitses, Dynamic Buckling of Imperfect Cylindrical Shells Under Axial Compression and Bending Moment, AIAA Journal. vol. 35, no. 8, August 1997.

2. C.C. Chamis and M.C. Shiao, Probabilistic Assessment of Smart Composite Structures, NASA TM 106358, 1993.

3. P.L.N. Murthy and C.C. Chamis, Integrated Composite Analyzer (ICAN): Users and Programmers Manual. NASA TP-2515, 1986.

4. S. Nakazawa, J.B. Dias, and M.S. Spiegel, The MHOST Finite Element Program: 3-D Inelastic Analysis Methods for Hot Section Components: Volume II-User's Manual, NASA Contractor Report $182235,1989$.

5. C.C. Chamis and J.H. Sinclair, Computer Code for Intraply Hybrid Composite Design, NASA TP2239, 1983.

6. Chamis, C.C. and Shiao, M.C., IPACS - Integrated Probabilistic Assessment of Composite Structures: Code Development and Applications. Third NASA Advanced Composite Technology Conference, vol. 1, pt. 2, NASA CP-3178-VOL-1-PT-2, 1993, pp. 987-999.

7. MSC NASTRAN 2001-Quick Reference Guide. MSC Software Corporation, Los Angeles, CA, 2001.

8. Wu, Y.-T., Demonstration of a New Fast Probability Integration Method for Reliability Analysis, Advances of Aerospace Structural Analysis, ASME, pp. 63-73, 1985.

Table 1.-Probabilistic Dynamic Buckling of a Smart Composite Shell Primitive Variables, Scatter, Standard Deviation and Distribution $(1 \mathrm{psi}=6.9 \mathrm{paj} ; 1 \mathrm{lb}=4.445 \mathrm{~N}$.)

\begin{tabular}{|c|c|c|c|c|}
\hline$\underline{\text { Primitive Variable }}$ & $\underline{\text { Mean }}$ & $\%$ Scatter & $\frac{\text { Standard }}{\text { Deviation }}$ & $\frac{\text { Probabilistic }}{\underline{\text { Distribution }}}$ \\
\hline \multicolumn{5}{|l|}{ Graphite Epoxy } \\
\hline Fiber Modulus Ef11 (msi) & 31 & $\pm 5 \%$ & 1.55 & Normal \\
\hline Fiber Shear Modulus Gf12 (msi) & 2 & $\pm 10 \%$ & 0.2 & Normal \\
\hline Matrix Modulus Em (msi) & 0.50 & $\pm 10 \%$ & 0.05 & Normal \\
\hline Fiber Density $\left(\mathrm{lb} / \mathrm{in}^{3}\right)$ & 0.0630 & $\pm 10 \%$ & 0.0063 & LogNormal \\
\hline Matrix Density $\left(\mathrm{lb} / \mathrm{in}^{3}\right)$ & 0.0443 & $\pm 10 \%$ & 0.00443 & LogNormal \\
\hline Fiber Volume Ratio & 0.65 & $\pm 10 \%$ & 0.065 & Normal \\
\hline Void Volume Ratio & 0.050 & $\pm 15 \%$ & 0.0075 & LogNormal \\
\hline Outer Ply Angle $\left(45^{\circ}\right)$ & 45.0 & $\pm 6.66 \%$ & 3.0 & Normal \\
\hline Ply Thickness (in.) & 0.005 & $\pm 5 \%$ & 0.00025 & LogNormal \\
\hline \multicolumn{5}{|l|}{$\underline{\text { Smart Material }}$} \\
\hline Fiber Modulus Ef11 (msi) & 11.9 & $\pm 5 \%$ & 0.595 & Normal \\
\hline Fiber Shear Modulus Gf12 (msi) & 4.5 & $\pm 10 \%$ & 0.45 & Normal \\
\hline Fiber Volume Ratio & 0.65 & $\pm 10 \%$ & 0.065 & Normal \\
\hline Volume Fraction & 0.50 & $\pm 10 \%$ & 0.05 & LogNormal \\
\hline Ply Angle $\left(-45^{\circ}\right)$ & -45.0 & $\pm 6.66 \%$ & 3.0 & Normal \\
\hline Ply Thickness (in.) & 0.005 & $\pm 5 \%$ & 0.00025 & LogNormal \\
\hline Electric Field Strength (V/in) & $1.0 \mathrm{E} 06$ & $\pm 10 \%$ & $1.0 \mathrm{E} 05$ & Normal \\
\hline Field Strain Coefficient (in/V) & 4.8E-09 & $\pm 10 \%$ & $4.0 \mathrm{E}-10$ & LogNormal \\
\hline
\end{tabular}




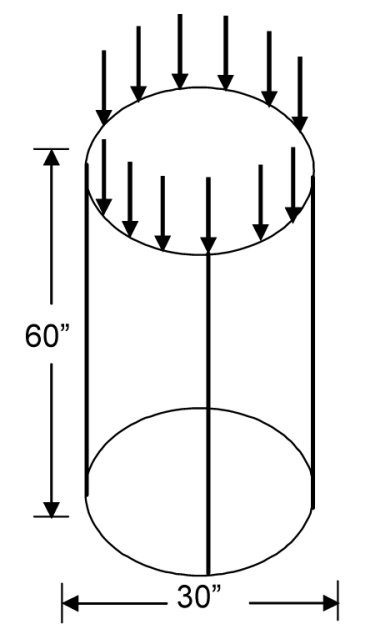

Material and loading configurations

- Graphite epoxy: [ $\left.(45,-45,0,90)_{7},-45,45\right]$

- Ply thickness: 0.005 in.

- Total thickness: 0.15 in.

- Fiber volume ratio: 0.65

- Void volume ratio: 0.05

- Time step for dynamic analysis: $0.00025 \mathrm{sec}$

- Total time considered for dynamic analysis: $0.05 \mathrm{sec}$

- 20 Kips dynamic load is applied in equal increment.

- Buckling analysis is performed at the end of each time step using updated deformed geometry.

Figure 1.-Buckling of a clamped-clamped composite shell subject to dynamic compressive axial loading. $(1 \mathrm{in} .=2.54 \mathrm{~cm} ; 1 \mathrm{kip}=4.445 \mathrm{KN}$.

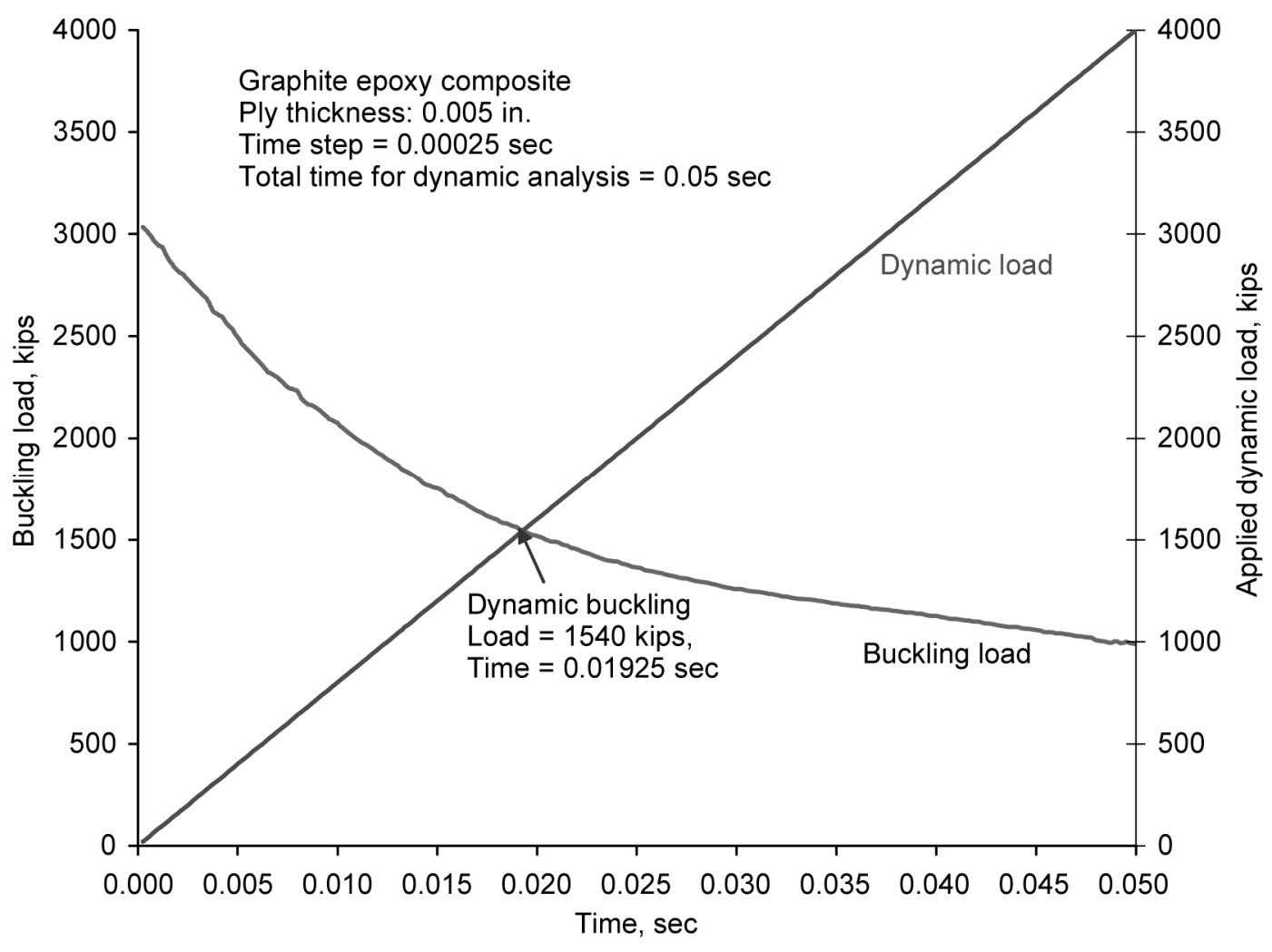

Figure 2.-Effect of time on the buckling load and applied dynamic load (composite shell with dynamic compressive axial loading $)$. (1 kip $=4.45 \mathrm{mn})$. 
(a)
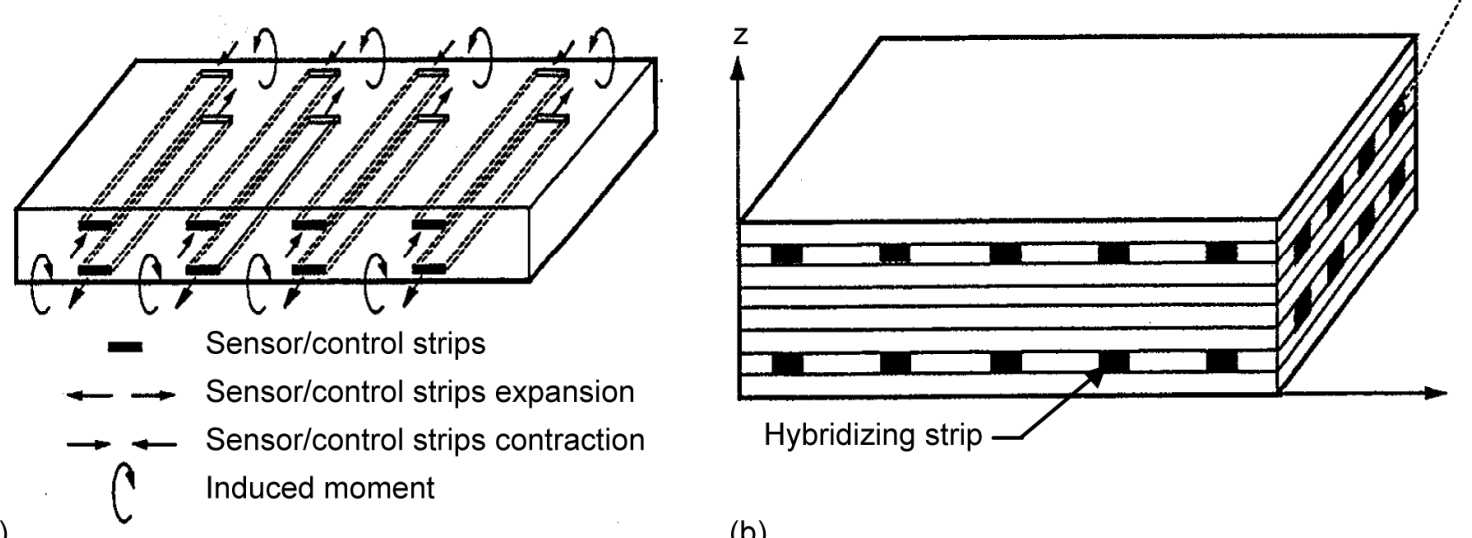

(b)

Figure 3.-Adaptation of intraply hybrid to smart composite system. (a) Intraply hybrid composite system.

(b) Structural control using sensor/control materials.

\begin{tabular}{|l|c|}
\hline \multicolumn{2}{|c|}{ Smart fiber properties } \\
\hline Modulus $\mathrm{E}_{11}$ (Mpsi) & 11.9 \\
\hline Modulus $\mathrm{E}_{22}$ (Mpsi) & 11.9 \\
\hline Modulus $\mathrm{E}_{33}$ (Mpsi) & 11.9 \\
\hline Poisson's ratio $\mathrm{v}_{12}$ & 0.31 \\
\hline $\begin{array}{c}\text { Poisson's ratio } \mathrm{v}_{23} \\
\text { Shear Modulus } \mathrm{G}_{12} \\
\text { (Mpsi) }\end{array}$ & 0.31 \\
\hline $\begin{array}{c}\text { Strain coefficient } \\
\text { (in } \mathrm{N} \text { ) }\end{array}$ & $4.5 \times 10^{-9}$ \\
\hline $\begin{array}{c}\text { Electric field strength } \\
\text { (V/in.) }\end{array}$ & $1.0 \times 10^{6}$ \\
\hline $\begin{array}{c}\text { Smart composite } \\
\text { volume fraction }\end{array}$ & 0.5 \\
\hline
\end{tabular}

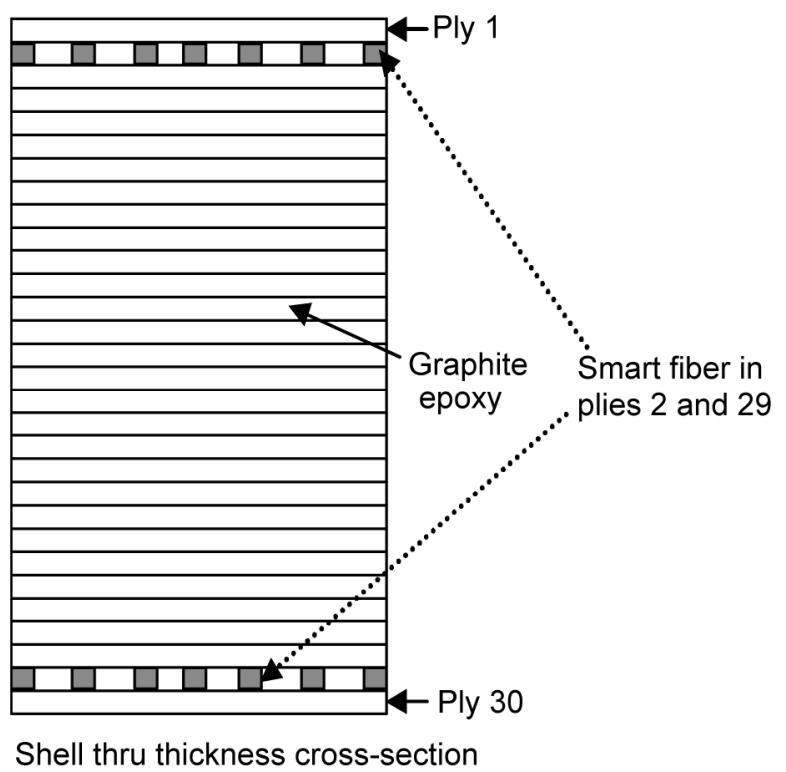

Figure 4.-Properties of smart fiber and adaptation of smart composite material.

$(1 \mathrm{psi}=6.9 \mathrm{~Pa} ; 1 \mathrm{in} . / \mathrm{V}=2.54 \mathrm{~cm} / \mathrm{V} ; 1 \mathrm{~V} /$ in. $=0.4 \mathrm{~V} / \mathrm{cm})$. 


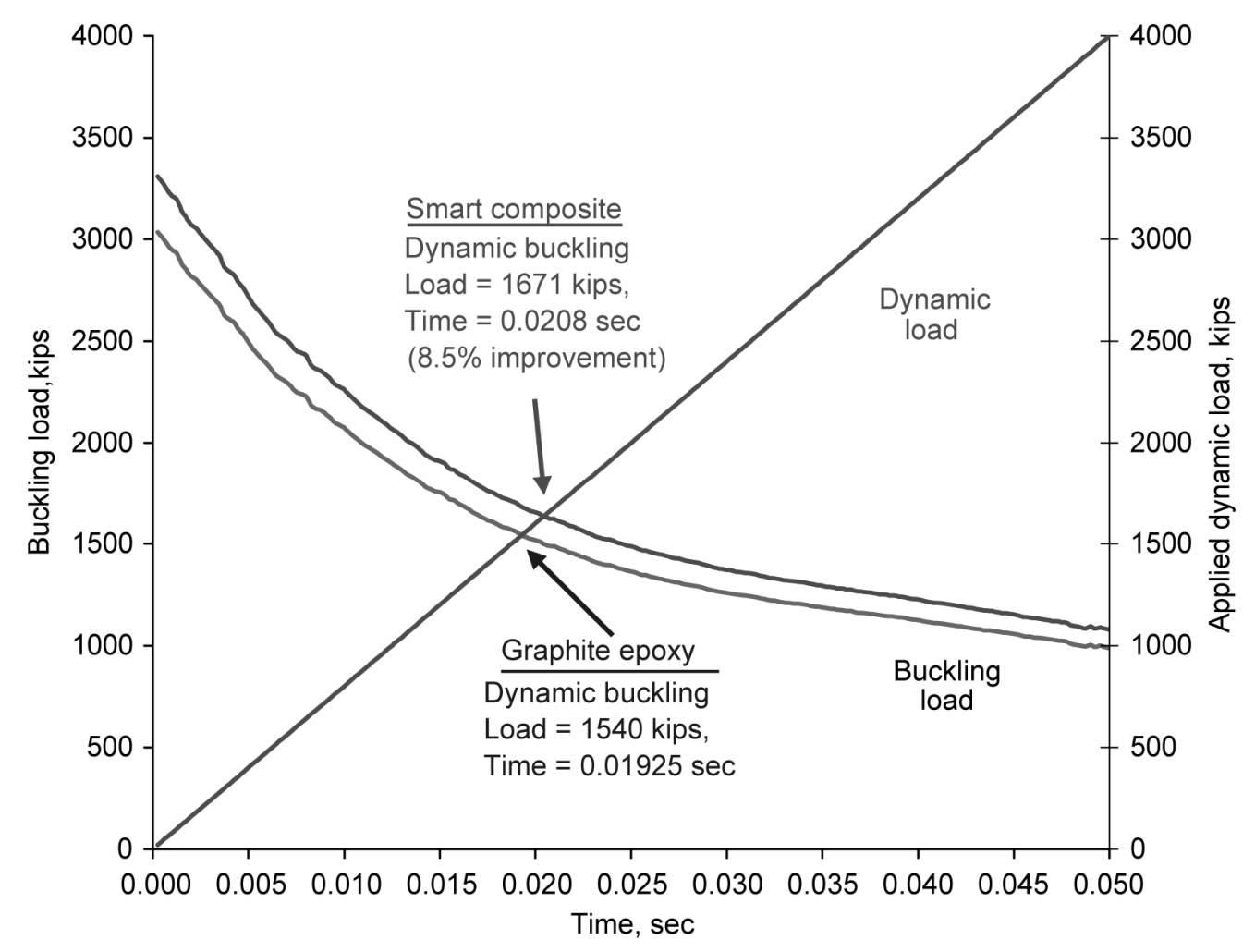

Figure 5.-Estimation of dynamic buckling load of smart and graphite epoxy composite shells.

$(1 \mathrm{kip}=4.45 \mathrm{mn})$.

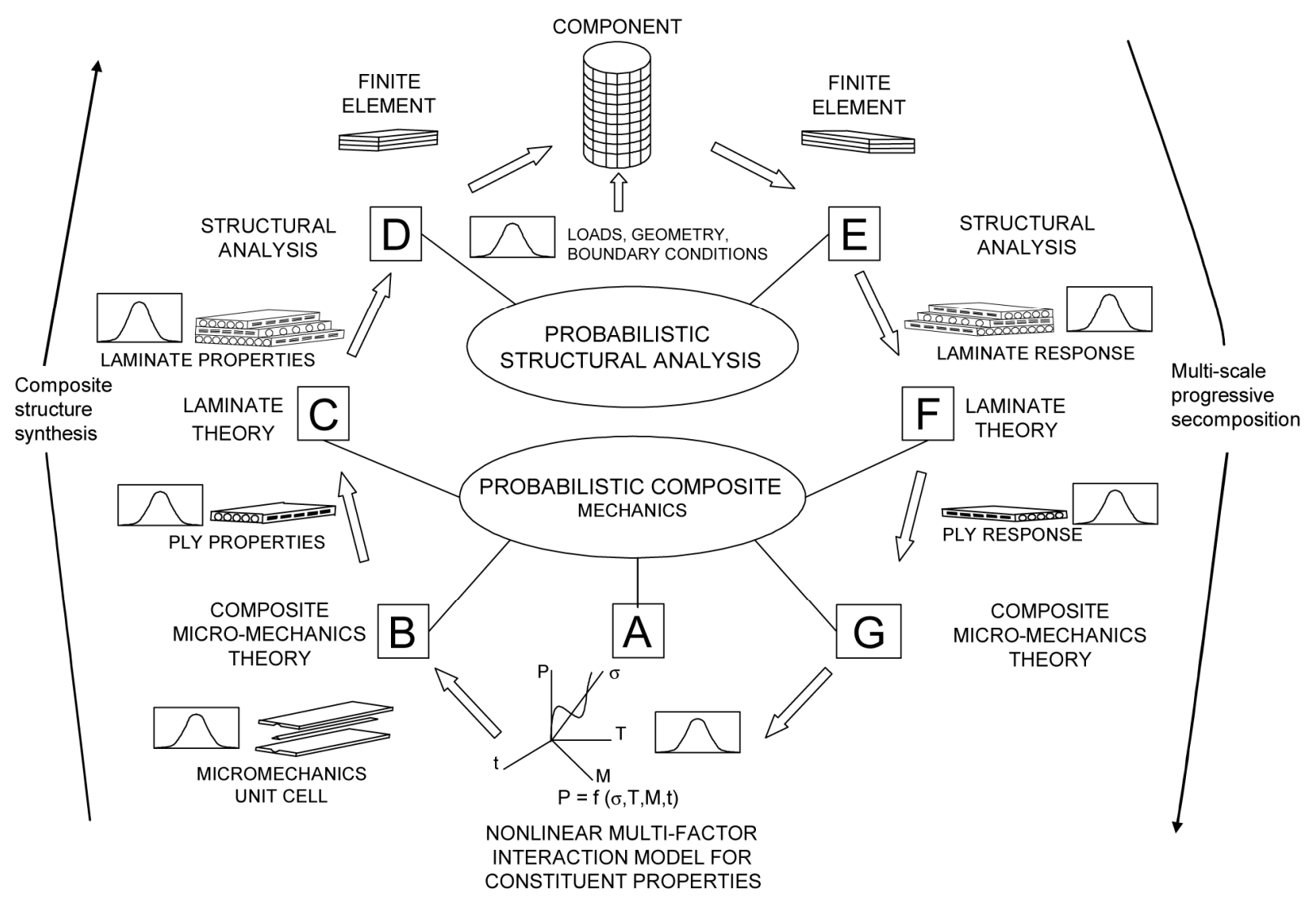

Figure 6.--Modular chart for the IPACS computer. 


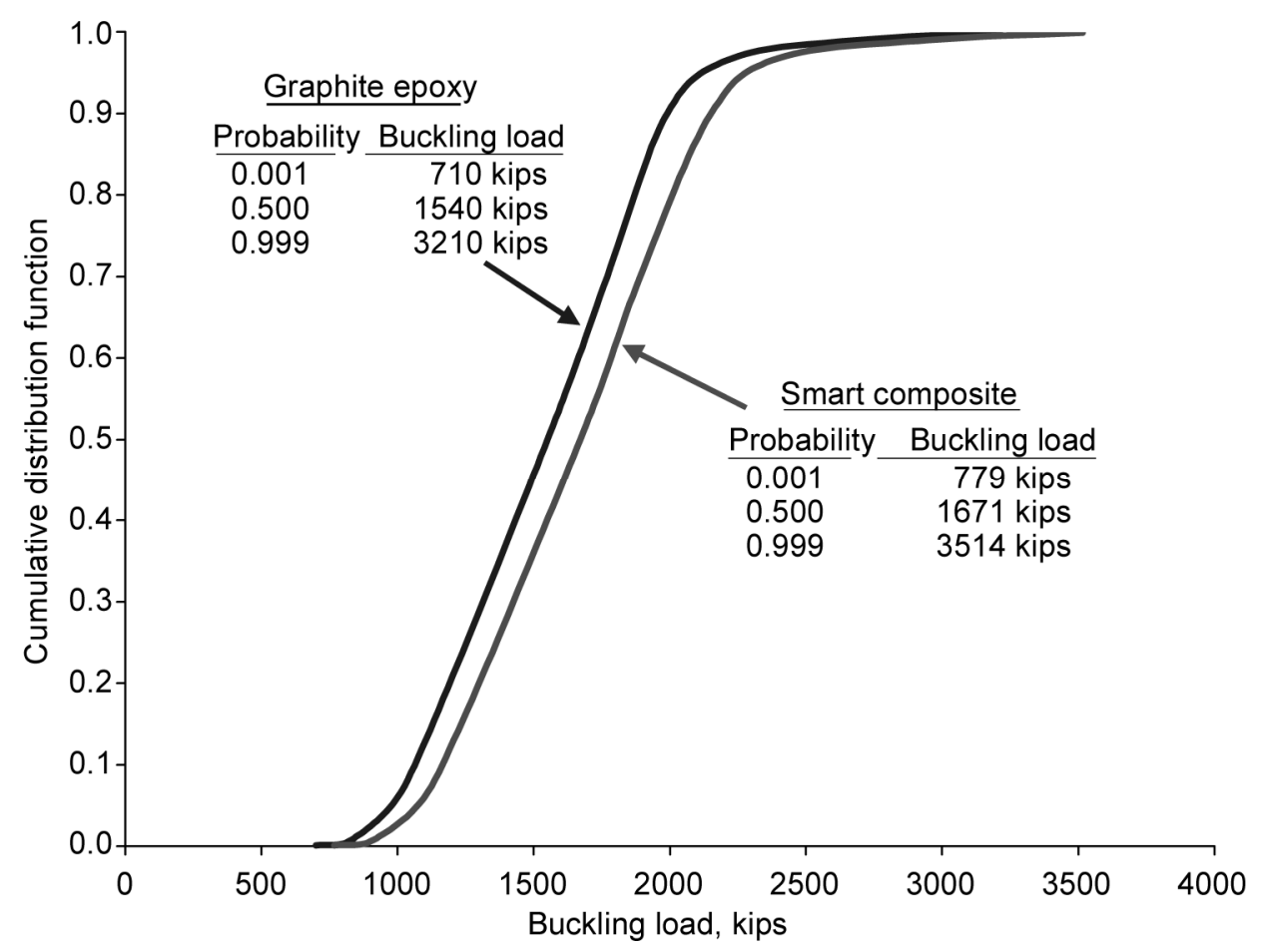

Figure 7.-Probabilistic evaluation of dynamic buckling load of graphite epoxy and smart composite shells. $(1 \mathrm{kip}=4.45 \mathrm{mn})$.

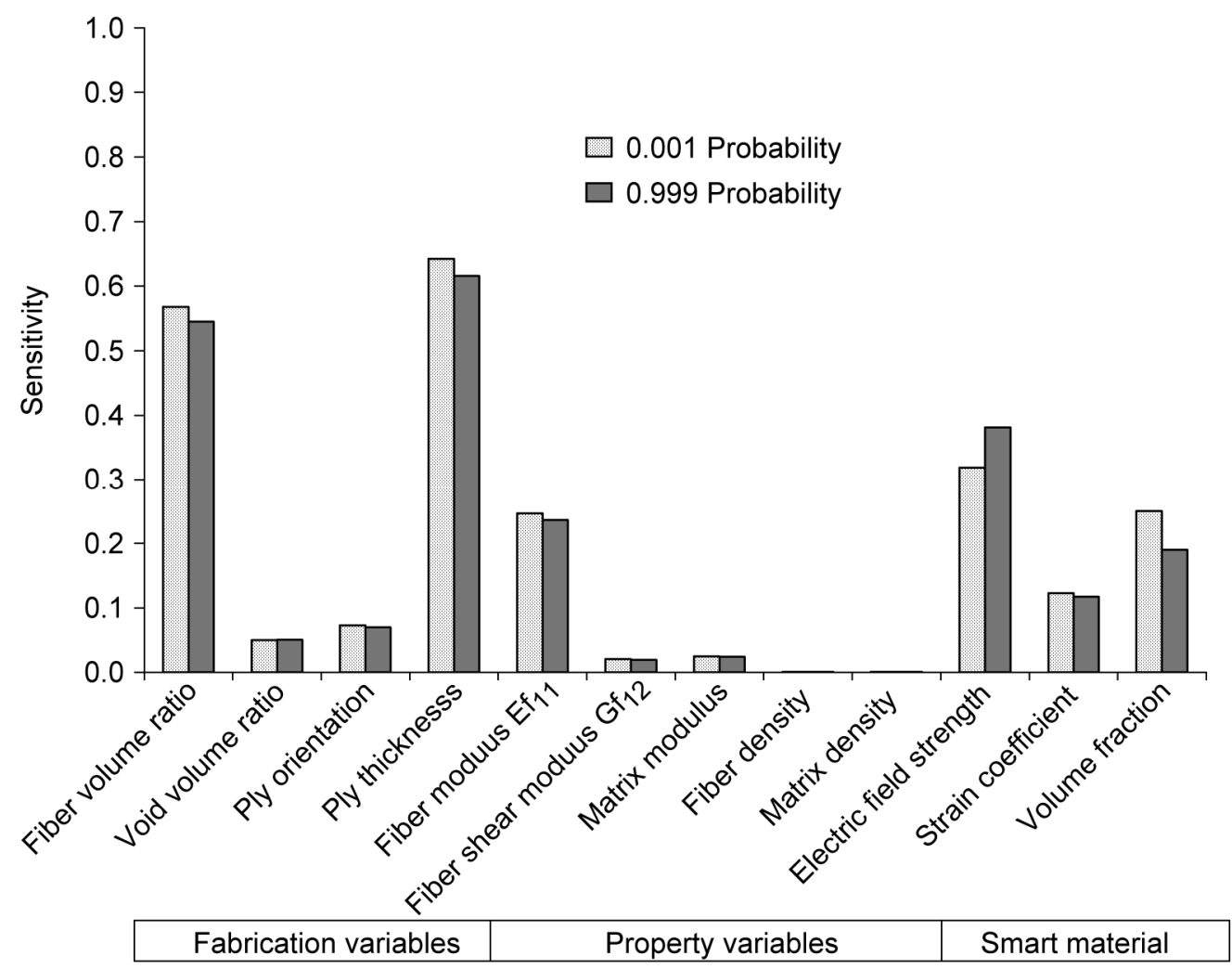

Figure 8.-Probabilistic sensitivities of dynamic buckling load of a smart composite shell. 


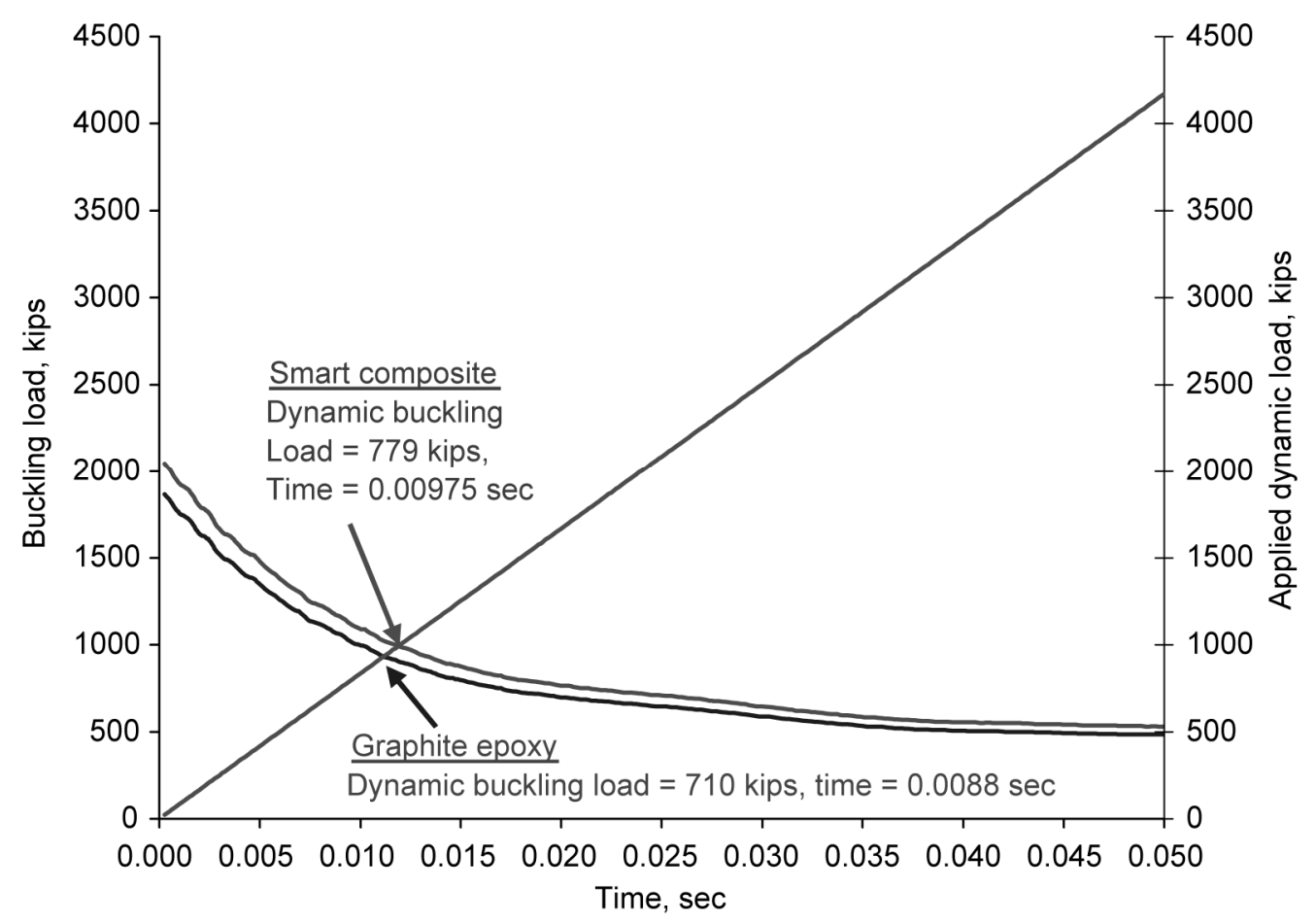

Figure 9.-Dynamic buckling load of graphite epoxy and smart composite shells at 0.001 probability. (1 kip $=4.45 \mathrm{mn})$.

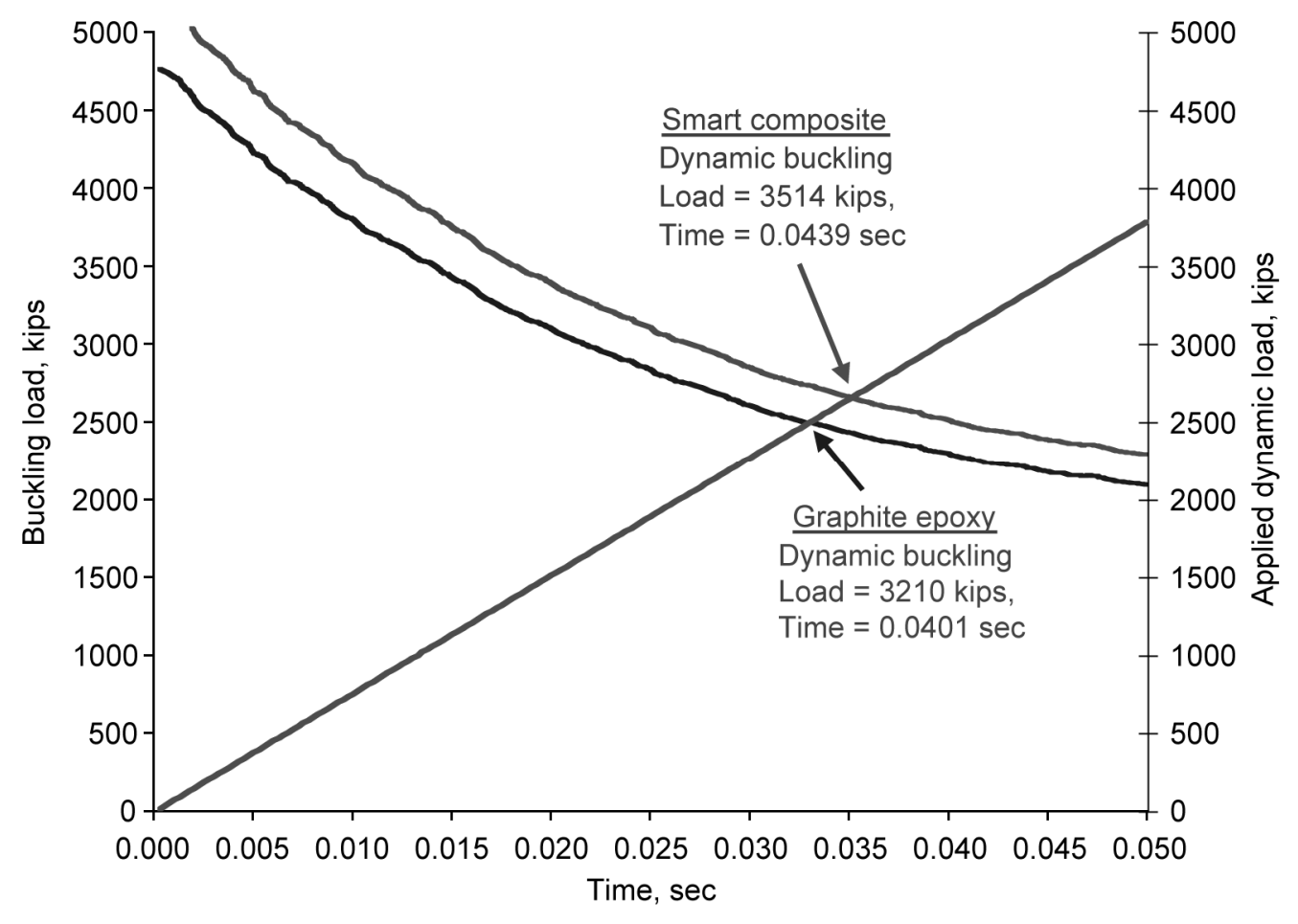

Figure 10.-Dynamic buckling load of graphite epoxy and smart composite shells at 0.999 probability. (1 kip $=4.45 \mathrm{mn})$. 


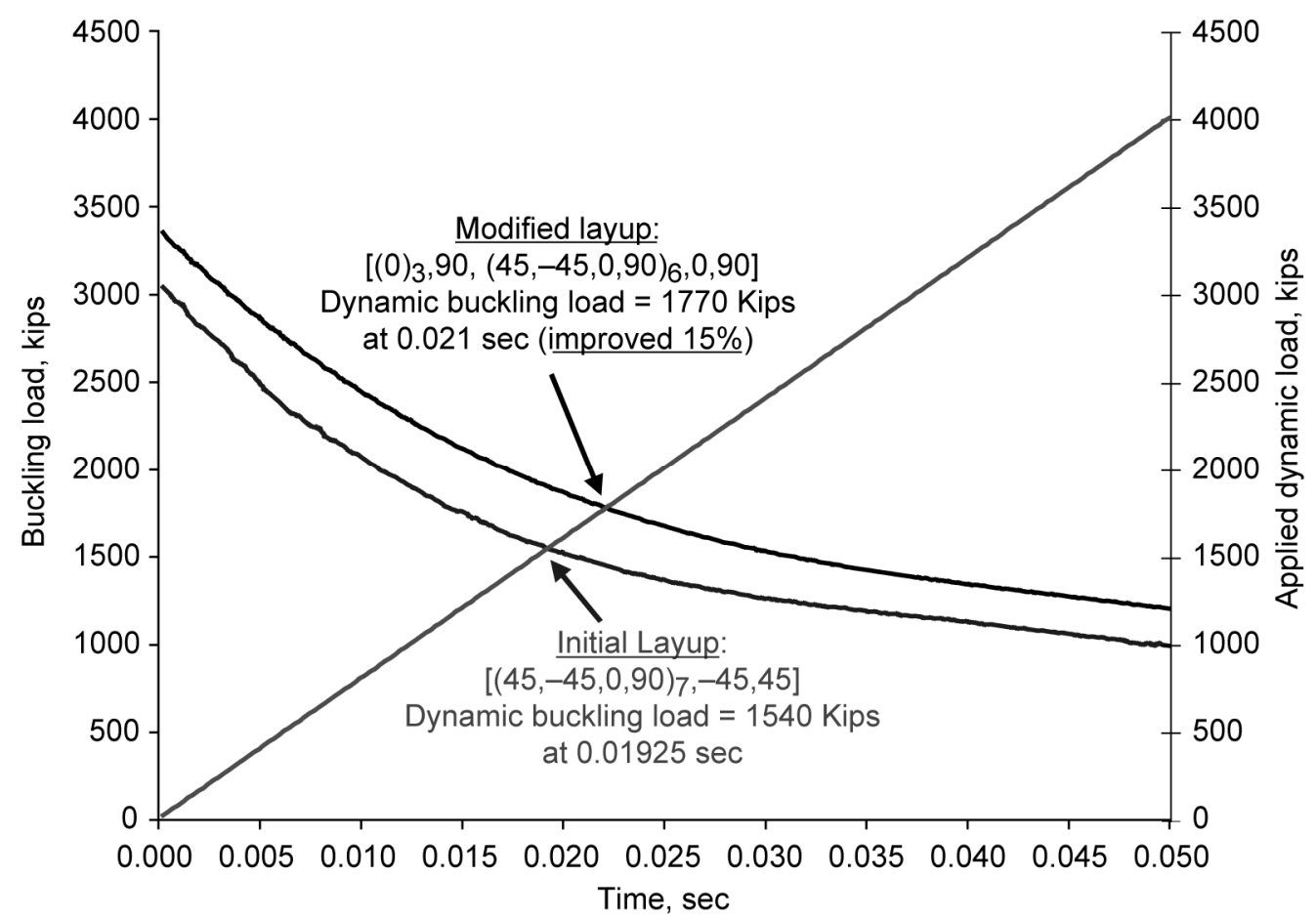

Figure 11.-Benefit of using $0^{\circ}$ and $90^{\circ}$ graphite fibers in plies 1 and 30 on the dynamic buckling of a graphite epoxy composite shell. $(1 \mathrm{kip}=4.45 \mathrm{mn})$.

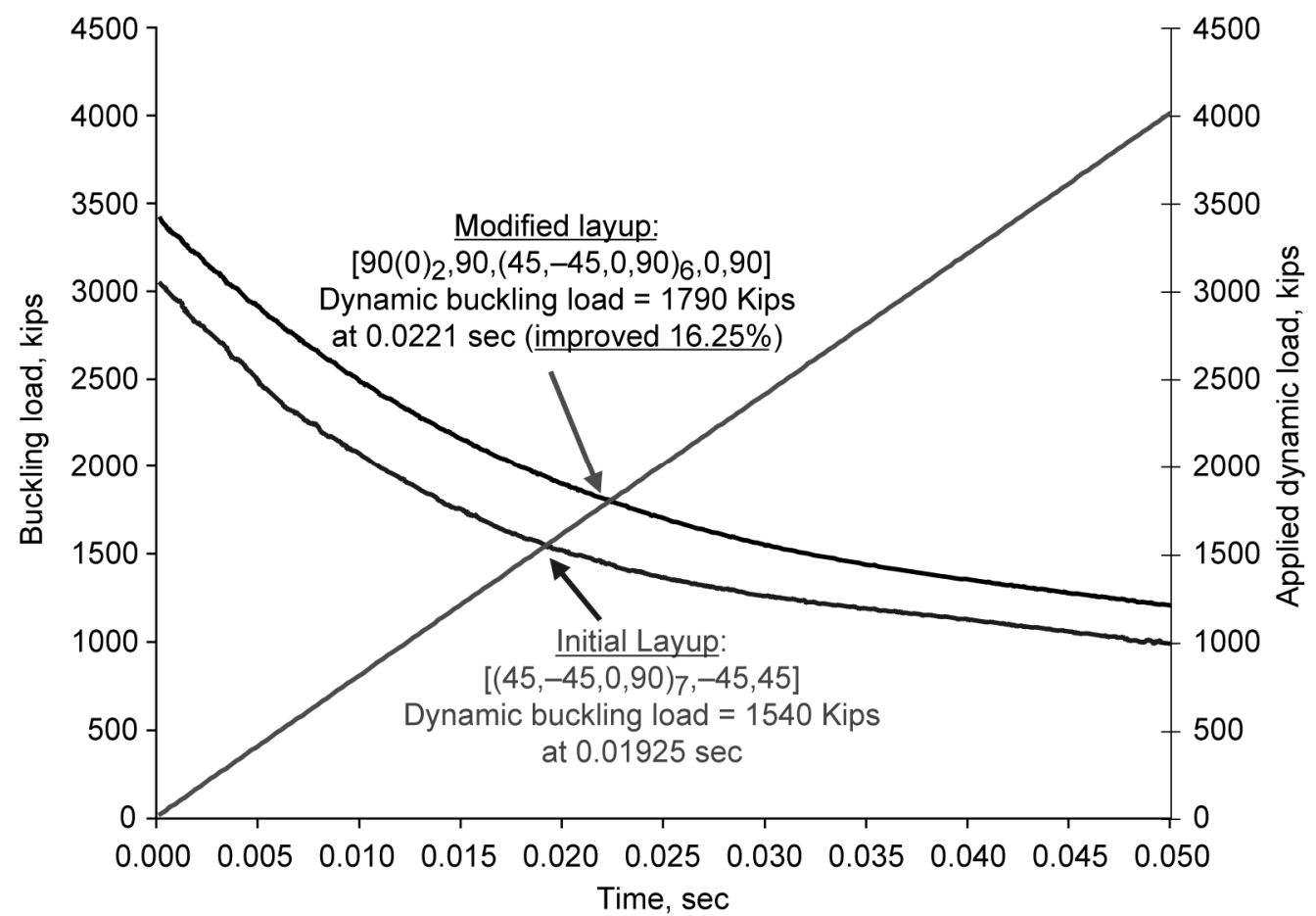

Figure 12.-Benefit of using $90^{\circ}$ graphite fibers in plies 1 and 30 on the dynamic buckling load of a graphite epoxy composite shell. $(1 \mathrm{kip}=4.45 \mathrm{mn})$. 


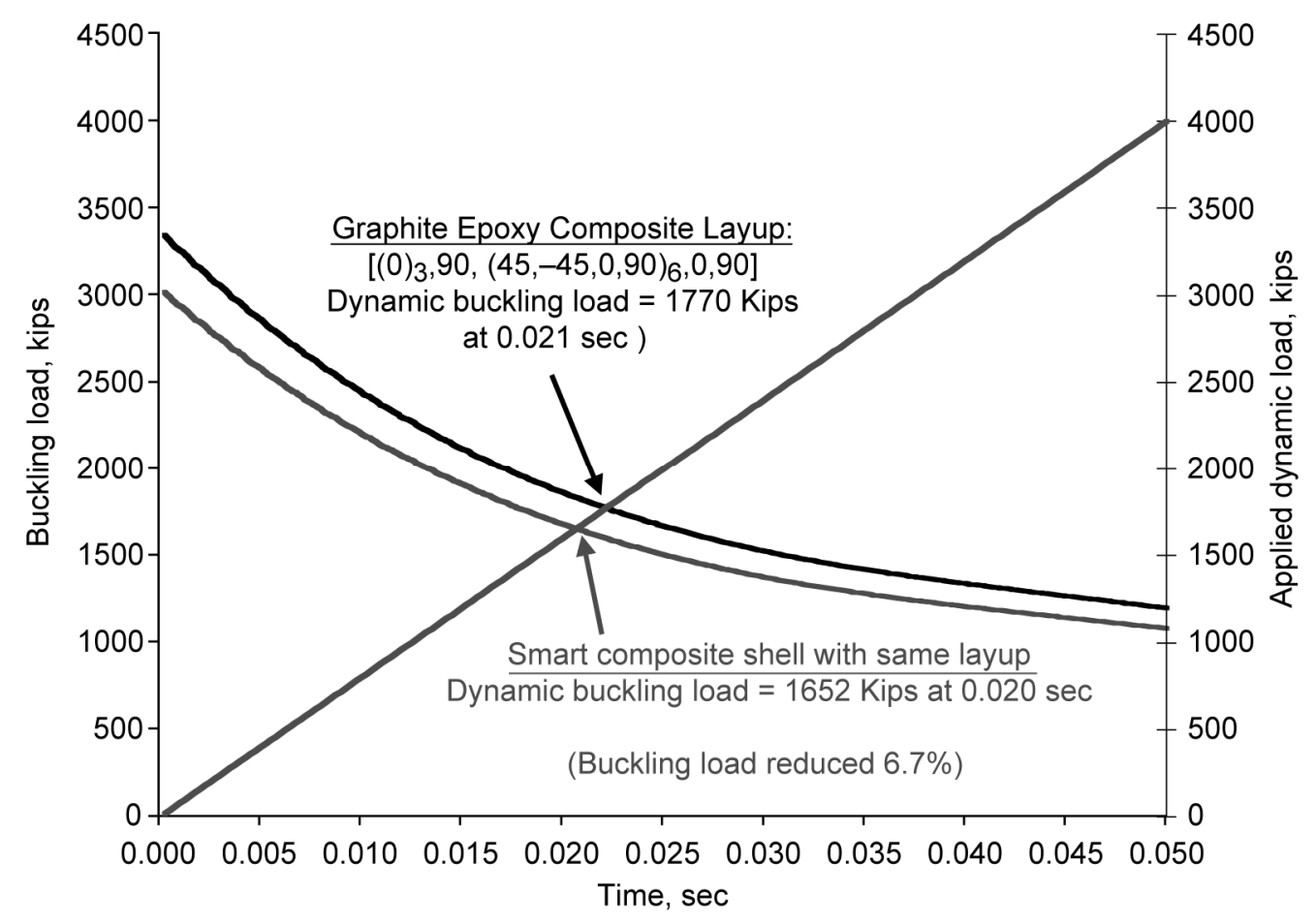

Figure 13.-Dynamic buckling load of a smart composite shell with $0^{\circ}$ and $90^{\circ}$ graphite fibers in plies 1 and 30. $(1 \mathrm{kip}=4.45 \mathrm{mn})$.

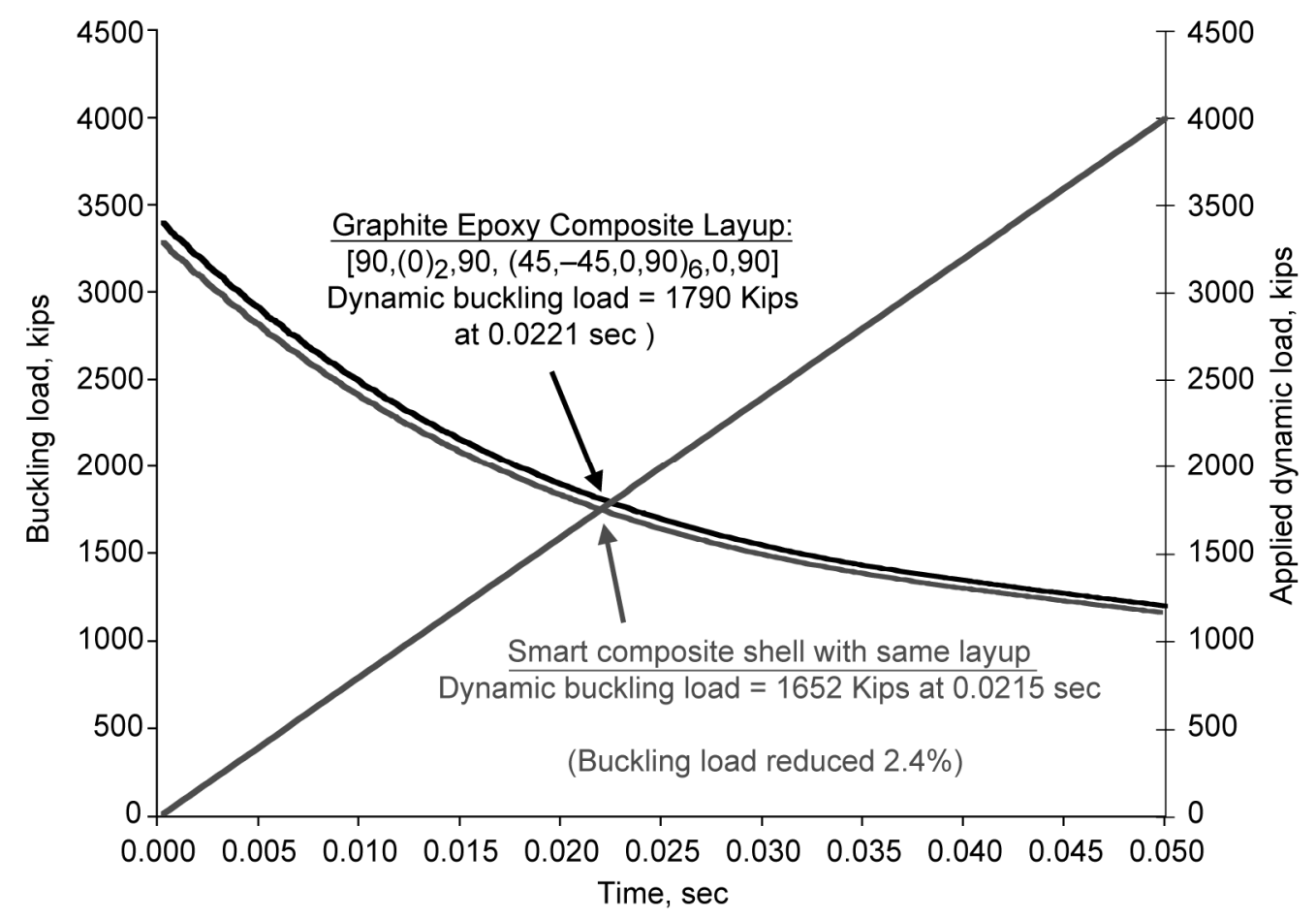

Figure 14.-Dynamic buckling load of a smart composite shell with $90^{\circ}$ graphite fibers in plies 1 and 30. $(1 \mathrm{kip}=4.45 \mathrm{mn})$. 


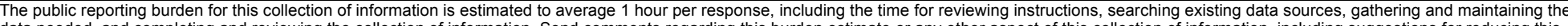

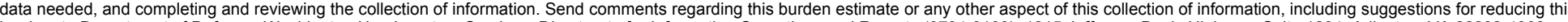

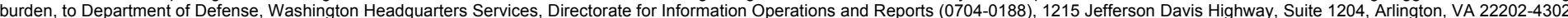

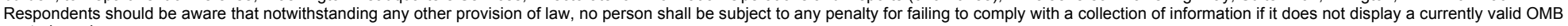
control number.

PLEASE DO NOT RETURN YOUR FORM TO THE ABOVE ADDRESS.
1. REPORT DATE (DD-MM-YYYY)
2. REPORT TYPE
3. DATES COVERED (From - To)

01-11-2008

Technical Memorandum

\section{TITLE AND SUBTITLE}

Assuring Life in Composite Systems

\section{5a. CONTRACT NUMBER}

5b. GRANT NUMBER

5c. PROGRAM ELEMENT NUMBER

\section{AUTHOR(S)}

Chamis, Christos, C

\section{5d. PROJECT NUMBER}

5e. TASK NUMBER

5f. WORK UNIT NUMBER

WBS 659877.02.03.0573.01

8. PERFORMING ORGANIZATION REPORT NUMBER

E-16526-1

National Aeronautics and Space Administration

John H. Glenn Research Center at Lewis Field

Cleveland, Ohio 44135-3191

9. SPONSORING/MONITORING AGENCY NAME(S) AND ADDRESS(ES)

National Aeronautics and Space Administration

Washington, DC 20546-0001

10. SPONSORING/MONITORS
ACRONYM(S)
NASA
11. SPONSORING/MONITORING
REPORT NUMBER
NASA/TM-2008-215452

\section{DISTRIBUTION/AVAILABILITY STATEMENT}

Unclassified-Unlimited

Subject Categories: 39 and 24

Available electronically at http://gltrs.grc.nasa.gov

This publication is available from the NASA Center for AeroSpace Information, 301-621-0390

\section{SUPPLEMENTARY NOTES}

\section{ABSTRACT}

A computational simulation method is presented to assure life in composite systems by using dynamic buckling of smart composite shells as an example. The combined use of composite mechanics, finite element computer codes, and probabilistic analysis enable the effective assessment of the dynamic buckling load of smart composite shells. A universal plot is generated to estimate the dynamic buckling load of composite shells at various load rates and probabilities. The shell structure is also evaluated with smart fibers embedded in the plies right below the outer plies. The results show that, on the average, the use of smart fibers improved the shell buckling resistance by about $9 \%$ at different probabilities and delayed the buckling occurrence time. The probabilistic sensitivities results indicate that uncertainties in the fiber volume ratio and ply thickness have major effects on the buckling load. The uncertainties in the electric field strength and smart material volume fraction have moderate effects and thereby in the assured life of the shell.

\section{SUBJECT TERMS}

Composite materials; Dynamic shell bucklings; Probability; Sensitivities

\begin{tabular}{|c|c|c|c|c|}
\hline \multicolumn{3}{|c|}{ 16. SECURITY CLASSIFICATION OF: } & \multirow{2}{*}{$\begin{array}{l}\text { 17. LIMITATION OF } \\
\text { ABSTRACT } \\
\text { UU }\end{array}$} & \multirow{2}{*}{$\begin{array}{l}\text { 18. NUMBER } \\
\text { OF } \\
\text { PAGES } \\
20\end{array}$} \\
\hline $\begin{array}{l}\text { a. REPORT } \\
\text { U }\end{array}$ & $\begin{array}{l}\text { b. ABSTRACT } \\
\mathrm{U}\end{array}$ & $\begin{array}{l}\text { c. THIS } \\
\text { PAGE } \\
\text { U }\end{array}$ & & \\
\hline
\end{tabular}

19a. NAME OF RESPONSIBLE PERSON STI Help Desk (email:help@sti.nasa.gov) 19b. TELEPHONE NUMBER (include area code) 301-621-0390 

